\title{
Menstrual Regulation Services and Post Menstrual Regulation Care in the Context of Bangladesh
}

\author{
Tasnim S \\ Department of Gynaecology, Institute of Child and Mother Health, Matuail, Dhaka-1362, Bangladesh
}

\begin{abstract}
Menstrual regulation (MR) program is an important component of reproductive health services that had been introduced to prevent abortion related deaths in Bangladesh. The service is provided through a nationwide network of government and non government facilities. Proper selection of cases and maintenance of quality of services are essential to prevent any complication and optimize its use.
\end{abstract}

Keywords: Abortion, complication, menstrual regulation (MR)

\section{INTRODUCTION}

The population of Bangladesh is 140.6 million and one fifth of it belongs to women of $15-49$ years age group. ${ }^{1}$ The contraceptive prevalence rate is $55.8 \%$ and there is an unmet need for family planning (FP) of $17.6 \%{ }^{1}$ The 1999 2000 BDHS data indicate that nearly $20 \%$ of women had a pregnancy termination at some point in their reproductive lives. ${ }^{2}$ Unsafe abortion is one of the main causes of maternal death in Bangladesh accounting $24 \%$ of the total maternal deaths. ${ }^{3}$

\section{What is MENSTRUAL REGULATION (MR) ?}

In Bangladesh, the penal code permits induced abortion only to save a woman's life. However, menstrual regulation (MR) by vacuum aspiration is not regulated by the code and is considered to be an "interim method for establishing nonpregnancy for a woman who is at risk of being pregnant, whether or not she is pregnant in fact". 4,5 The procedure is performed by vacuum aspiration and allowed up to 10 weeks since the last menstrual period but in practice, it is sometimes provided up to 12 weeks. ${ }^{6,7}$

\section{Number of MR Performed}

Accurate estimates of the annual number of procedures are not available, primarily due to a weak reporting system and the social stigma attached to MR and abortion may inhibit reporting. ${ }^{8}$ A study reveals that among the unintended pregnancies that are due to contraceptive failure $31 \%$ undergo menstrual regulation, $4.9 \%$ seek for induced abortion ${ }^{9}$. According to Amin et al, (1989) government service statistics captured only $29 \%$ of the total MRs. ${ }^{10}$ Since the mid-eighties, the number of MRs performed in the country reported by the MOHFW has remained at around 1000,000 annually. ${ }^{11}$

Several researchers have speculated that the reported number represents only a small fraction of the number of MR cases actually performed each year. In all, the practice of MR (both reported and unreported) saves at least 100,000 to 160,000 women in Bangladesh from the dangers of unsafe abortion every year. ${ }^{2}$ The 1999-2000 BDHS data indicate that nearly $20 \%$ of women had a pregnancy termination at some point in their reproductive lives. Every year $2.8 \%$ of all pregnant women undergo Menstrual Regulation (MR) and 1.5\% undergo induced abortion. ${ }^{12}$ Another study shows that $64 \%$ had accepted MR services within 8 weeks of conception and $11 \%$ received the service after 12 weeks of conception. ${ }^{13}$ About one-third of MR clients are rejected, since they turn up too late. ${ }^{14}$ Most of these late comers, along with those who do not have any information on MR, usually end up with traditional / non medical abortion providers. In theory, MR is provided free of charge by government hospitals and health facilities. In practice, however, that is often not true. ${ }^{15}$

\section{CORRESPONDENCE}

Dr. Saria Tasnim, FCPS, MMEd.

Department of Gynecology

Institute of Child and Mother Health

Matuail, Dhaka-1362, Bangladesh

Mobile : 01819221096

Email: sariatasnim2007@gmail.com 


\section{Availability of MR Service}

The government of Bangladesh began its MR program in 1974 in selected urban clinics with the objective of reducing the maternal death from unsafe abortion. A second reason for the need of MR services was to support the family planning program at an early stage in its development. ${ }^{15}$ In 1978, the Pathfinder Fund (with USAID funds) began a training and service program for MR in seven medical colleges and two government district hospitals. This was the start of what was to become the Menstrual Regulation Training and Services Program (MRTSP). The government followed this program in 1979 with a circular including MR in the national family planning program and encouraging service providers to offer MR service in all government hospitals and family planning centres. ${ }^{16}$ The public health facilities providing MR services include District hospitals, Maternal and Child Welfare Centres (MCWC), Upazilla Health Complexes (UHC), and Union Health and Family Welfare Centres (UH \& FWC). In addition, some government training centres/model clinics e.g. Mohammadpur Fertility Services and Training Centre also offer MR services. A limited number of NGOs are also involved in MR service provision. These include Bangladesh Association for the Prevention of Septic Abortion (BAPSA); the Bangladesh Women's Health Coalition (BWHC), the Menstrual Regulation Training and Services Program (MRTSP), Marie Stopes Clinic Society (MSCS), Family Planning Association of Bangladesh (FPAB) and Bangladesh Rural Advancement Committee (BRAC). ${ }^{17}$ All NGOs except MRTSP provide services in their own facilities. MRTSP provides MR services at government medical colleges and district hospitals.

Although MR is not a family planning method, however, in some occasion it can be used to help contraceptive user if their method fails. The MR services are provided in the same government clinical settings as family planning and $\mathrm{MCH}$ services. The indication of MR is depicted in Table 1.

Table 1. Indication of MR

\begin{tabular}{|c|c|c|}
\hline Family planning & $\begin{array}{l}\text { Medical condition } \\
\text { that is aggravated } \\
\text { in pregnancy }\end{array}$ & $\begin{array}{l}\text { Diseases where } \\
\text { treatment is } \\
\text { interfered by } \\
\text { Pregnancy }\end{array}$ \\
\hline $\begin{array}{l}\text { Contraceptive } \\
\text { failure } \\
\text { Unwanted } \\
\text { Pregnancy }\end{array}$ & $\begin{array}{l}\text { Heart Disease } \\
\text { Sever Bronchial } \\
\text { Asthma } \\
\text { Kidney Disease } \\
\text { Liver Disease }\end{array}$ & $\begin{array}{l}\text { Malignant } \\
\text { conditions }\end{array}$ \\
\hline
\end{tabular}

\section{Complications}

Hospitalization or additional treatment is rarely required for MR. With vacuum aspiration, the lower the gestational age, the lower the rate of complications. ${ }^{18,19}$ At 7 to 8 weeks gestation a $3.9 \%$ complication rate is expected. ${ }^{18}$ With outpatient menstrual regulation, performed within 6 weeks of last menstrual period, complications occurred in $1.3 \%$ of 614 cases. $^{18}$
Table 2. Complications of MR

\begin{tabular}{lll}
\hline Immediate & Delayed & \multicolumn{1}{c}{ Late } \\
\hline Vasovagal attack & Incomplete & Asherman syndrome \\
Heavy bleeding & MR & Amenorrohea \\
Perforation of & Septic & Haematometra \\
uterus & abortion & Infertility \\
Cervical tear/ & Failed MR & Pelvic Inflammatory \\
laceration & & Disease \\
& & Rh iso-immunization \\
\hline
\end{tabular}

The overall rate of hospitalization for abortion is 2.4 per 1000 live births and about $75 \%$ of these complications are due to unsafe abortion and the remainder is due to menstrual regulation. The annual estimated number of complications requiring hospitalization that result from MR is about 19,300 , which is approximately $4 \%$ of the 468,000 MR performed annually. ${ }^{20}$ Although induced abortion is illegal in Bangladesh, the practice is believed to be common in about 26-30 per 1000 live births. ${ }^{21}$ Approximately half of the admissions to gynaecology units in major urban hospitals of the country are for complications of abortion. Induced abortion other than menstrual regulation is estimated to have a complication rate of about $40 \%$ and a hospitalization rate of about $20 \% .^{22}$ Table 2 describes the complications of MR.

Certain precautions should be taken before performing MR to minimize chances of complications. These include a detail history taking regarding menstrual history, obstetric history, medical history and any drug reaction to exclude any risk factor. A thorough general, abdominal and bimanual examination should be done. Blood grouping with Rh typing should be done to prevent chance of isoimmunization and estimation of blood sugar is necessary for diabetics. Proper analgesia and strict asepsis should be maintained.

\section{Post MR Care and Counseling}

This is an important activity to save women's lives from complications of MR and help them to adopt an appropriate method and prevent another unwanted pregnancy. Evidence shows that about $15 \%$ of the women had repeated abortion..$^{23}$ The higher the previous abortion exposure the more likely they are to intend to terminate pregnancy in future, if needed. ${ }^{24}$ This highlights the importance of post-

Table 3. Contraceptive choice among MR (No.) clients after the procedure at ICMH

\begin{tabular}{llllll}
\hline Year & MR & Oral pill & Condom & IUD & Total \\
\hline 2005 & 125 & 34 & 45 & 46 & 250 \\
2006 & 124 & 51 & 59 & 14 & 248 \\
2007 & 162 & 108 & 28 & 26 & 324 \\
2008 & 264 & 163 & 45 & 56 & 528 \\
2009 & 262 & 112 & 83 & 67 & 524 \\
2010 & 186 & 84 & 59 & 43 & 352 \\
\hline
\end{tabular}


Tasnim. Menstrual Regulation Services and Post MR Care in the Context of Bangladesh

abortion contraceptive counselling. All modern methods are acceptable provided that thorough counseling is given to ensure voluntarism and choice and clients are screened for any risk factors. Table 3 shows contraceptive choice of MR clients over a period of 5 years in the family planning clinic of institute of child and mother health (ICMH) which is located in a periurban area. ${ }^{25}$ It showed that most of the women preferred short acting temporary method and only $20 \%$ accepted intrauterine device as contraceptive method following menstrual regulation.

\section{CONCLUSIONS}

MR program occupies a unique position in reproductive health services in Bangladesh. The Bangladesh Maternal Health Services and Maternal Mortality Survey, 2001 reported a significant decrease in abortion-related deaths and that has been attributed to the improved accessibility to (MR) services. ${ }^{3}$ However, a number of procedures are performed privately by untrained personnel which add to the number of unsafe abortion and are threat to maternal health. Judicious use of MR service and strict scrutiny of the program is necessary to maintain quality and increase the efficiency and effectiveness of the program.

\section{REFERENCES}

1. BDHS. Bangladesh Demographic and Health Survey 2007. National Institute of Population Research and Training (NIPORT). Dhaka: Mitra and Associates; March 2009.

2. BDHS. Bangladesh Demographic and Health Survey 1999-2000. National Institute of Population Research and Training (NIPORT). Dhaka: Mitra and Associates;2001.

3. BMMS. Bangladesh Maternal Health Services and Maternal Mortality Survey 2001. NIPORT, MEASURE/DHS+ORC MACRO. Dhaka: Mitra and Associates; March 2002.

4. Akhter HH. Medical practice after legalization of abortion: Bangladesh prevention and treatment of contraceptive failure. Prevention and treatment of contraceptive failure -- In honor of Christopher Tietze edited by U. Landy and SS Ratnam. New York :Plenum Press;1986.

5. Dixon-Muller R. Innovations in reproductive health care: Menstrual regulation policies and programs in Bangladesh. Studies in Family Planning.1988;20: 2.

6. Akhter $\mathrm{HH}$. Bangladesh. In: P Sachdev, editor. International handbook on Abortion. New York: Greenwood Press;1988.37p.

7. Bangladesh Association for Prevention of Septic Abortion. Dhaka:MR Newsletter; Mar 1996.

8. Caldwell B, Khuda B, Ahmed S, Nessa F, Haque I. The determinants and consequences of pregnancy termination in rural Bangladesh: The wider context. Working Paper No. 131, MCH-FP Extension Project. Dhaka, Bangladesh: International Centre for Diarrhoeal Diseases Research;1997.
9. Akhter $\mathrm{HH}$. Scope of emergency contraception in Bangladesh Proceedings of the emergency contraception workshop. Dhaka: Population Council;1997.

10. Amin R, Kamal GM, Begum SF, Kamal H. Menstrual Regulation training and service programs in Bangladesh: Results from national survey. Studies in Family Planning.1989;20 (2):102-6.

11. Rob $U$, Ahmed T. Menstrual regulation program in Bangladesh: Policy and programmatic issues. Paper presented at American public health association's annual meeting. Washington DC;1996.

12. Ministry of Health and Family Welfare, Population and Development Post-ICPD achievements and Challenges - Bangladesh Country Report. Dhaka: Ministry of Health and Family Welfare, United Nations Population Fund (UNFPA); February 1999.

13. Rob U, Islam MM, Chakroborty N, Mutahara MU. Dynamics of menstrual regulation practices in Bangladesh. Dhaka: Population Council, Dhaka, Bangladesh and Department of Statistics, Dhaka University; 2002.

14. Ahmed YH. Emergency contraception enhancing women's choice for prevention of unwanted pregnancy in Bangladesh. Paper presented at the workshop on emergency contraception. Dhaka: Population Council; 1997.

15. Piet-Pelon NJ, Rob U. Menstrual regulation: past, present and future challenges. Policy dialogue. No 9. Dhaka, Bangladesh: Population Council; 1999.

16. Akhter $\mathrm{HH}$, Karim $\mathrm{F}$, Ahmed $\mathrm{YH}$, Chowdhury ME, Rahman $\mathrm{MH}$ Khan AR. A study to access the determinants and consequences of abortion in Bangladesh. Dhaka: Bangladesh Institute of Research for Promotion of Essential and Reproductive Health Technologies (BIRPERHT); 1998.

17. Ross G \& Chowdhury SNM (1997). Interim Program Review of the Bangladesh National Menstrual Regulation Training Program 19951997, IWHC for SIDA

18. Edelman DA, Brenner WE, and Berger G. The relative risks of Abortion by Suction Curettage and by Dilatation and Curettage. Presented at the $101^{\text {st }}$ Annual Meeting of American Public Health Association, San Francisco, Nov. 4-8, 1973

19. Tietze C, and Lewit S. Joint Program for the Study of Abortion (JPSA): Early Medical Complications of Legal Abortion. Stud Fam Plann.1972; 3:( 6) :97.

20. Singh S, Cabigon JV, Hossain A, Kamal H and Perez AE. Estimating the Level of Abortion in the Philippines and Bangladesh. International Family Planning Perspective 1997; 23: 100-107 \& 144.

21. www.searo. Who.int/reproductive-health profile. unwanted pregnancy/unsafe abortion accessed on 25.10.2010.

22. Chowdhury SNM, Kabir M, Hossain A. "MR Programme in Bangladesh: Challenges for the Future". Background paper prepared for the project. A Situation Analysis of Bangladesh Menstrual Regulation Programme. Reproductive Health Alliance 2002.

23. Ahmed S, Parveen SD, Islam A and Khanum PA. "Induced Abortion Results from Two Rural Areas of Bangladesh". Working Paper No. 142. Operation Research Project. Dhaka, Bangladesh: International Centre for Diarrhoeal Diseases Research, Bangladesh (ICDDR,B) 1997

24. Akhter $\mathrm{HH}$, Karim F, Ahmed $\mathrm{YH}$, Chowdhury MEEK, Rahman $\mathrm{MH}$ and Khan AR. "A study to Access the Determinants and Consequences of Abortion in Bangladesh". Dhaka: Bangladesh Institute of Research for Promotion of Essential and Reproductive Health Technologies (BIRPERHT) 1998.

25. Statistical Year Book. Department of Gynaecology and Obstetrics. Dhaka: Institute of child and mother health; 2010. 